\title{
Single-frame multiparameter platforms for seafloor geophysical and environmental observations: projects and missions from GEOSTAR to ORION
}

\author{
P. Favali, L. Beranzoli, M. Calcara, G. D'Anna, G. Etiope*, F. Frugoni, N. Lo Bue, G. Marinaro, S. Monna, C. \\ Montuori, T Sgroi, Istituto Nazionale di Geofisica e Vulcanologia \\ Via di Vigna Murata 605 \\ Roma, 00143, Italy \\ geostar@ingv.it \\ F. Gasparoni, S. Cenedese, F. Furlan, Tecnomare-ENI SpA \\ Venezia, Italy \\ G. Ferentinos, G. Papatheodorou, D. Christodolou, Dept. of Geology, University of Patras \\ Patras, Greece \\ J. Blandin, J. Marvaldi, J.-F.Rolin, IFREMER \\ Plouzane, France \\ G. Clauss, Technische University of Berlin \\ Berlin, Germany \\ H. Gerber, Technischefachhochschule Berlin, \\ Berlin, Germany \\ J.-M. Coudeville, M. Nicot, Sercel (former ORCA Instrumentation) \\ Brest, France \\ E. Flueh, GEOMAR \\ Kiel, Germany \\ F. Gamberi, M. P. Marani, ISMAR-CNR Sezione di Bologna \\ Bologna, Italy \\ G. Neri, University of Messina \\ Messina, Italy \\ * Corresponding Author
}

\begin{abstract}
The paper presents an overview of recent seafloor long-term single-frame multiparameter platform developed in the framework of the European Commission and Italian projects starting from the GEOSTAR prototype. The main features of the different systems are described as well as the sea missions that led to their validation. The ORION seafloor observatory network recently developed, based on the GEOSTAR-type platforms and engaged in a deep-sea mission at $3300 \mathrm{~m}$ w.d. in the Mediterranean Sea, is also described.
\end{abstract}

\section{INTRODUCTION}

The European experience on seafloor monitoring started in early ' 90 s under the Marine Science and Technology (MAST) Program of the European Commission (EC). Feasibility studies commissioned by EC were addressed to establish the basic technologies for a prototype of underwater multidisciplinary observatory intended as a single-frame unmanned platform to be relinquished on deep seafloor for long-term observations and assisted from the sea-surface (see DESIBEL-DEep-Sea Intervention on future BEnthic Laboratory and ABEL-Abyssal Benthic Laboratory feasibility studies; [5], [12], [13]. Between 1995 and 2001 the EC funded the GEOSTAR (GEophysical and Oceanographic STation for Abyssal Research) and GEOSTAR-2 projects [1], [2], [3]. These projects designed, developed and operated an autonomous deep-sea observatory (hereafter referred to as GEOSTAR) comprising a wide range of sensors in a single frame and providing facilities for external experiments. The GEOSTAR assets are the capability of multidisciplinary, long-term monitoring (up to 1 year) providing time referenced data series related to different seafloor processes in a site; the sea surface management according to an innovative approach; the possibility to transmit data in near-real-time through a surface buoy. The GEOSTAR system passed two different missions at sea in shallow and deep waters which confirmed its reliability and the feasibility of the deployment/recovery procedure even in moderately perturbed sea state.

Other three single-frame systems were developed sharing the basic features of GEOSTAR: SN-1, GMM and MABEL. The SN-1 (Submarine Network-1) system, is a multiparameter observatory mainly devoted to seismological and oceanographic measurements developed within a project funded by the Italian national Group for the Defence against Earthquakes (GNDT).

GMM (Gas Monitoring Module) is a new system for gas monitoring at seafloor developed within ASSEM (Array of Sensors for long-term SEabed Monitoring of geohazards; uww.ifremer.fr/assem) an other European Commission project mainly addressed to shallow water monitoring,

An other single-frame system, MABEL (Multidisciplinary Antarctic BEnthic Laboratory), is under development for polar sea applications in the framework of the Italian National Programme for Research in Antarctica.

The consolidation of the GEOSTAR experience, has allowed to take a step forward the ocean networking. In the framework of a new EC project, ORION-GEOSTAR-3 (Ocean Research by Integrated Observatory Networks), 
GEOSTAR was implemented to act as the main node of an underwater network of deep-sea observatories of GEOSTAR-type. The ORION system was developed in parallel to the already mentioned ASSEM project and one of the ORION observatory was integrated in the ASSEM system. This integration was to demonstrate the compatibility of the two monitoring systems and consequently the possibility to operate a coast-deep-sea monitoring system.

The paper describes the main features and missions of the GEOSTAR systems and of the systems derived. Also a short presentation of the data acquired during the completed experiments is given.

\section{THE GEOSTAR SYSTEM: FEATURES AND MISSIONS}

GEOSTAR is based on a two-module scheme: the Bottom Station (BS) or actual seafloor observatory, and MODUS (MObile Docker for Underwater Sciences) devoted to deployment and recovery of the BS. For the sake of brevity, readers interested to a detailed description of the system devices are addressed to [7], [9], [10], [11]. The BS is a four-leg frame hosting the monitoring system including lithium batteries for power supply of sensors and devices; electronics mounted inside titanium vessels; hard disks for data storage; communication systems; scientific and status sensors. Table I shows the size, weight and set of sensors of GEOSTAR (GEO).

The Data Acquisition and Control System (DACS) is an intelligent unit driving and controlling the BS. It is able to perform the following tasks: management and acquisition from all scientific packages and status sensors; preparation and continuous update of hourly data messages to be transmitted on request including event detection; actuation of commands received (e.g., data request, system reconfiguration, restart) back-up of data on internal memory. The DACS can manages a wide set of data streams with quite different sampling rates $(100 \mathrm{~Hz}$ to 1 sample/day) tagging each datum according to a unique reference time set by a central high-precision clock. MODUS, a simplified ROV, is the special vehicle for GEOSTAR deployment and recovery. It is driven from a ship through a dedicated opto-electro-mechanical cable and is equipped with a latch/release device and thrusters mounted on a cone shaped frame to load, move and place the BS. MODUS frame is also equipped with video cameras for seabed visual inspection, compass to measure the orientation of the BS, sonar and altimeter. Fig. 1 shows the scheme of the management of GEOSTAR and GEOSTAR-type modules by means of MODUS.

During the GEOSTAR missions, the BS was also equipped with Communication System (CS) originally developed and consisting of buoyant capsules for data storage released by the BS: the Messengers (MES) [11]. An additional communication system based on a standard bi-directional Acoustic Telemetry System ("vertical acoustic link") is also mounted on the BS.

The GEOSTAR prototype systems performed its first sea mission in shallow waters [1], [3]. The observatory was deployed on August 13 th, 1998 on the seafloor of the Adriatic Sea (Northern Italy, see GEOSTAR 1 in Fig. 2) in 42 $\mathrm{m}$ w.d., about $50 \mathrm{~km}$ east of the Ravenna harbour and recovered after 21 days. The deployment and recovery operations were performed with the support of the $R N$

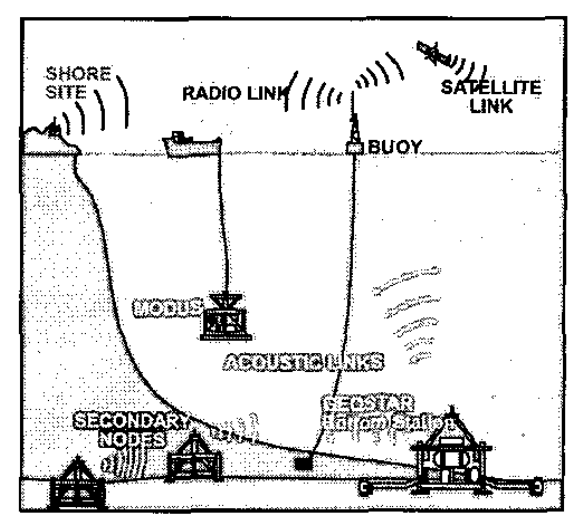

Fig. 1. Scheme of management and operation of the ORION network of seafloor observatories of GEOSTAR type. The network is operated from the sea surface by MODUS, a dedicated vehicle, and communicates with land through a buoy via acoustics-radio-satellite system.

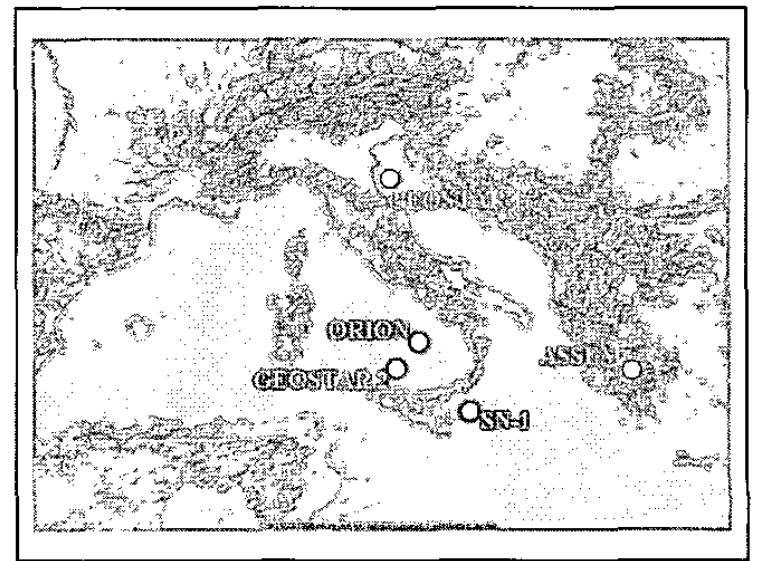

Fig. 2. Locations of the seafloor missions of GEOSTAR and derived platforms. GMM and one of the ORION nodes (Node 4) are integrated inside the ASSEM array.

Urania, managed by Italian National Research Council (CNR). The selection of the mission site was based both on the knowledge of geological and geotechnical soil characteristics (flat and consolidated seafloor, distance from turbulence source, absence of pockmarks and gassy sediments) and safety factors (shallow water depth, vicinity to harbour logistics).

The mission configuration of the BS comprised a 3-axial broad-band seismometer, scalar and vectorial magnetometers, an Acoustic Doppler Current Profiler (ADCP), a Conductivity Temperature and Depth sensor (CTD) and a light-transmissometer

The sensors were selected in order to maintain a power consumption lower than $350 \mathrm{~mA}$ at $24 \mathrm{~V}$. Special care was taken in the choice of the electronic components of the bi-axial magnetometer, a prototype developed by INGV. To reduce disturbance of the BS frame and electronics, devices were designed and implemented to install the seismometer and magnetometers. The former, installed in a benthosphere by the supplier, was then included inside a cylindrical heavy housing. To guarantee a good coupling with the sea bottom, 
a special release device was adopted: the whole package is released after the BS touch-down and kept linked to the BS frame by a slack rope. The magnetometers were installed at the extremity of two booms attached on opposite vertices of the BS frame to keep them as far as possible from electronic noise sources. The booms, kept vertical during the deployment descent, are extended upon command once the BS is placed on the seafloor (see Fig. 3a on the right).

The starting mission procedure foresees that after the BS touch-down, all sensor packages and devices are switched on through MODUS telemetry and their correct functioning is checked. After the positive outcome of this operation, the BS is definitively released by the MODUS and left on the sea bottom. During the shallow water mission around 346 Mbytes of data, stored in the BS hard disks, were acquired over roughly 440 operational hours, corresponding to $97.8 \%$ of the mission's duration ( -450 hours). One Messenger was released upon acoustic command by an operator on board the RN Urania just before the recovery operations. Temporary magnetic and seismological stations were aiso installed on land as a reference for GEOSTAR measurements A detailed description of the shallow water mission and the scientific results can be found in [1], [3].

After the GEOSTAR shallow water demonstration mission, the MODUS was enhanced for deep-sea missions.

In the period September 2000-April 2001 a long-term deep-sea mission ( 7 months) was conducted at $2000 \mathrm{~m} \mathrm{w.d}$. in the southern Tyrihenian Sea (see GEOSTAR 2 in Fig. 2). The GEOSTAR observatory was equipped with an enriched set of sensors. For this mission, the CS was improved with a surface moored buoy for near real-time communication between the BS and onshore sites providing the interface of the acoustic system with a radio/satellite communication link. During the deep-sea mission the GEOSTAR platform hosted also an hydrophone provided by GEOMAR (German research institution) as an external sensor: it was fastened to a leg of the observatory frame with autonomous power supply and acquisition. Unfortunately, because of rough sea state during the sea operations, the seismometer knocked on the ship wall and a damage to the benthosphere occurred. In order to avoid risk of water intrusion, the sensor was dismounted from the observatory before the deployment. The hydrophone and a gravity meter were in this occasion useful redundancy.

The data acquired in 174 days of mission (around 4160 hours) amount to more than 65 Mbyte mostly from the gravity meter. The external hydrophone acquired 4 Gbyte of data.

\section{SINGLE-FRAME SYSTEMS DERIVED FROM GEOSTAR}

\section{A. $\mathrm{SN}-1$}

$\mathrm{SN}-1$ (Fig. 3b) is a reduce size version of GEOSTAR and represents the recent effort of the Italian marine research addressed to the realisation of a seafloor network in the Italian Seas.

$\mathrm{SN}-1$ has the basically the same features of GEOSTAR with respect to deployment/recovery procedures based on MODUS, the data acquisition system and the special device for seismometer installation. It hosts a reduced set of sensors, in comparison to GEOSTAR, which are mainly seismological and oceanographic (Table I). Differently from GEOSTAR, SN-1 has a standard acoustic equipment inside the BS and is not supported by a surface moored buoy.

From October 2002 to May 2003 SN-1 successfully completed a long-term mission offshore Catania (Southern Italy, Eastern Sicily) at $2105 \mathrm{~m}$ w.d.. During the mission, $\mathrm{SN}-1$ acquired in autonomous mode, around 10 Gbytes of data, 7.65 Gbytes of which belong to $100 \mathrm{~Hz}$ sampling rate broad-band seismometer [8]. SN-1 demonstrates the relevant improvement of the seismic event detection obtainable with the presence of an observation site at sea acquiring hundreds of events not recorded on land. In the next future, $\mathrm{SN}-1$ observatory will be deployed again and connected to a submarine cable owned and already deployed by the Italian National Institute for Nuclear Physics (INFN). Some power and fibre optic lines of this cable will be made available to the observatory through a suitable

TABLE I

MAIN CHARACTERISTICS OF GEOSTAR-TYPE PLATFORMS

\begin{tabular}{|c|c|c|c|}
\hline Platform & $\begin{array}{l}\text { Dimensions } \\
(\mathrm{m})\end{array}$ & $\begin{array}{l}\text { Weight } \\
\text { (kg) }\end{array}$ & Equipment's \\
\hline GEO* & $3.5 \times 3.5 \times 2.9$ & $\begin{array}{c}2900 \\
(\approx 1500 \text { in } \\
\text { water })\end{array}$ & $\begin{array}{c}\text { Broad-band } \\
\text { Seismometer } \\
\text { Scal. and Vect. } \\
\text { Magnetometers } \\
\text { ADCP and CTD } \\
\text { Transmissometer } \\
\text { 3D Current-meter } \\
\text { Gravity-meter^ } \\
\text { Hydrophone } \\
\text { Chemical analyser } \\
\text { Water sampler }\end{array}$ \\
\hline $\mathrm{SN}-1$ & $3.0 \times 3.0 \times 2.9$ & $\begin{array}{c}1400 \\
(\approx 800 \text { in } \\
\text { water })\end{array}$ & $\begin{array}{l}\text { Broad-band } \\
\text { Seismometer } \\
\text { Gravity-meter^ } \\
\text { Hydrophone } \\
\text { CTD } \\
\text { 3D Current-meter }\end{array}$ \\
\hline GMM & $1.5 \times 1.5 \times 1.5$ & $\begin{array}{l}150 \\
(\approx 70 \text { in } \\
\text { water })\end{array}$ & $\begin{array}{c}\text { Methane and } \\
\text { Sulphidric acid } \\
\text { sensor package } \\
\text { CTD }\end{array}$ \\
\hline MABEL & $3.0 \times 3.0 \times 2.9$ & $\begin{array}{c}1400 \\
(\approx 800 \text { in } \\
\text { water })\end{array}$ & $\begin{array}{c}\text { Broad-band } \\
\text { Seismometer } \\
\text { Scal. Magnetometer } \\
\text { Hydrophone } \\
\text { ADCP and CTD } \\
\text { 3D Current-meter } \\
\text { Chemical analyser }\end{array}$ \\
\hline $\begin{array}{l}\text { ORION } \\
\text { Node } 3\end{array}$ & $3.0 \times 3.0 \times 2.9$ & $\begin{array}{c}1400 \\
(\approx 800 \text { in } \\
\text { water })\end{array}$ & $\begin{array}{l}\text { Broad-band } \\
\text { Seismometer } \\
\text { 3D Current-meter } \\
\text { Hydrophone }\end{array}$ \\
\hline $\begin{array}{l}\text { ORION } \\
\text { Node } 4\end{array}$ & $2.0 \times 2.0 \times 2.0$ & $\begin{array}{c}650 \\
(\approx 350 \text { in } \\
\text { water })\end{array}$ & $\begin{array}{l}\text { Broad-band } \\
\text { Seismometer } \\
\text { 3D Current-meter } \\
\text { Hydrophone } \\
\text { Methane sensor }\end{array}$ \\
\hline
\end{tabular}

* Configuration in the ORION system

^ Prototype developed by Italian Istituto dello Spazio Interplanetario - Istituto Nazionale di Astrofisica in collaboration with INGV 
underwater junction box. In this way $\mathrm{SN}-1$ will receive power from shore and will be able to communicate in real-time with a shore station. This will make possible the complete integration of $\mathrm{SN}-1$ to the existing Italian land-based network, and significantly contribute to the knowledge of a key sector of the central Mediterranean geodynamics. The INFN cable will have also the purpose to carry out a scientific experiment of natural neutrino detection in deep-sea waters (NEMO Pilot Experiment). A scheme of the $\mathrm{SN}-1$ and NEMO joint projects is given in Fig. 4.

\section{B. GMM} the

An other system developed on the basis of the store of GEOSTAR experience, is a Gas Monitoring Module (GMM) designed and built up in the framework of the ASSEM project. GMM is an automatic, instrumented station designed to monitor gas occurrence in seawater close to seabed. The continuous long-term monitoring of methane and other gaseous compounds can clarify important aspects regarding concentration variability in seawater, flux, vent occurrence and ephemeral behaviour of vents (e.g., pockmarks, mud volcanoes) as well as their relationships with and to other processes (e.g., water circulation, seismicity, biological communities). GMM is based on a light benthic circular tripod of aluminium alloy (Fig. 3c). It can operate autonomously or can be interfaced to external units (e.g., other seafloor nodes of an underwater network, on-shore stations, communication buoys) via submarine cable. The system can be reconfigured to be integrated either in more complex observatories like GEOSTAR either operated as a payload of submarine vehicles for areal surveys. In particular. the GMM design allows modification of frame top for the management through MODUS by the installation of flanged extension tubes bolted directly to the feet. The GMM electronics performs the similar tasks as the GEOSTAR DACS.

The GMM configuration for ASSEM system, includes the payload listed in Table I. Three methane sensors are mounted in series ("revolver" type configuration), including one master and two back-up sensors. The back-up sensors replace the master one in case of failure or bad functioning; this strategy assures a longer operation of the system. A microsensor is installed in $\mathrm{GMM}$ for the detection $\mathrm{H}_{2} \mathrm{~S}$, which can be a trace component of seep gas. A CTD is also mounted on GMM. The redundancy of the temperature detection (provided both by the methane sensor and more accurately by the CTD) is useful to recognise eventual signal drifts of the methane sensors due to internal problems or to fouling on the membrane. Further interfaces are available for additional sensors. Six-month autonomous operation is possible with the $12 \mathrm{~V}, 960$ Ah lithium battery pack. GMM has been deployed in an active pockmark at $40 \mathrm{~m}$ w.d. in the Gulf of Patras (Corinth Shelf, central Greece) in April 2004 as one of the nodes of the ASSEM system. GMM has been collecting data and transmitting in real-time via cable to an on-shore modem. The deployment of GMM in the Gulf of Patras was not performed with the support of MODUS, given the shallow water depth; it was simply lowered down to the seafloor and checked during the descent through a standard acoustic system.
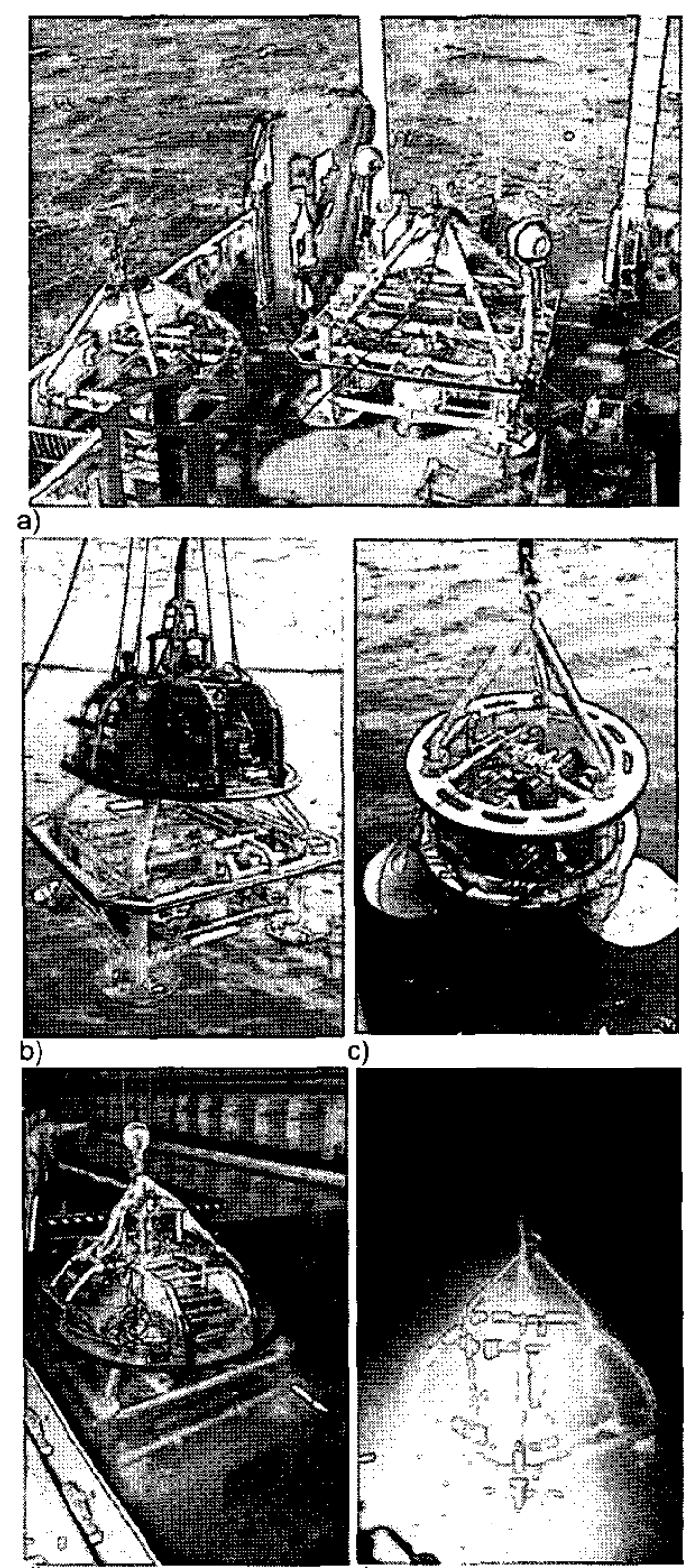

c)

d)

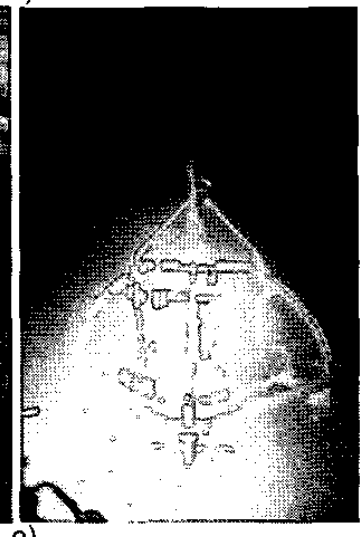

e)

Fig. 3. a) GEOSTAR single-frame seafloor observatory (right) and ORION Node 3 (left) on the deck of the RN Urania before the deployment at the base of Marsili underwater volcano (ORION mission); b) $\mathrm{SN}-1$ platform during the first deployment (eastern Sicily); c) GMM module during the deployment in the Gulf of Patras; d) MABEL observatory during a test phase in basin; e) ORION Node 4 on the seafloor of the Corinth Gulf (ASSEM mission).

\section{MABEL}

MABEL (Fig. 3d) is a deep-sea multiparameter observatory under development and addressed to the acquisition of geophysical, geochemical, oceanographic and 


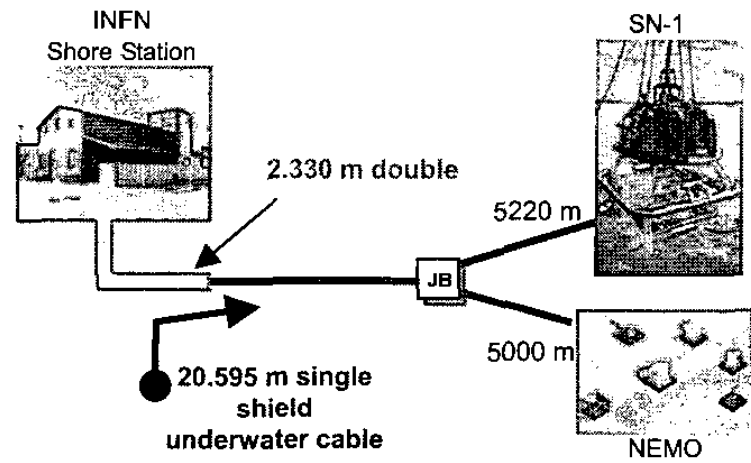

Fig. 4. Scheme of the joint experiment SN-1 and NEMO. Both systems will be cabled to onshore for power supply and real-time data transmission.

environmental time series on the seafloor of the polar regions [6]. MABEL is designed to operate autonomously for one year and will be the first seafloor observatory deployed in Antarctica. The scientific payload will include a broad-band seismometer, a hydrophone, a scalar magnetometer, a CTD, a 3D single-point current-meter, an ADCP current profiler and a chemical analyser (see Table I). This latter is a automatic prototype of package for long term measures in continuous mode developed by INGV in collaboration with Tecnomare and based on a commercial $\mathrm{pH}$ electrode. A first test of the chemical analyser prototype was already carried out in the southern Tyrrhenian Sea (Italy), at the base of the Marsili underwater volcanic edifice during the first ORION mission (see next section).

The first mission of MABEL is planned in the Weddell Sea (2005-6 and 2006-7) with the logistic support of the RN Polarstern managed by the Alfred Wegener Institute (Germany). MODUS will be used for the deployment of MABEL, and in this respect a set of additional tests on the latch/release device are already on-going to adapt the vehicle to the operation at low temperatures.

\section{THE ORION SYSTEM: FEATURES AND MISSION}

After the positive outcomes of the GEOSTAR missions (1998 and 2000-2001), the GEOSTAR BS, the surface buoy and MODUS were enhanced in order to be able to manage a network of observatories of GEOSTAR-type in the framework of the ORION-GEOSTAR-3 project. A picture with the general scheme of ORION is shown in Fig. 1. In particular the communication systems was enhanced in order to enable the GEOSTAR observatory to act as the main node of the ORION network, exchanging data and status parameters with satellite nodes.

GEOSTAR BS was thus equipped with an additional acoustic subsystem devoted to the communication among the nodes ("horizontal" acoustic link). Through the horizontal communication, GEOSTAR receives data from the satellite nodes while the original vertical communication is used to transmit data of the observatory network to the surface buoy. The horizontal modems fit with omni-directional antennas whereas the vertical acoustic link is performed with directional transducers. The acoustics subsystems are based on the MATS Modem (Multimodulation Acoustic Modem, developed by Sercel Underwater Acoustic Division, former Orca Instrumentation)) used by research institutes, Navies and offshore oil companies. The earlier functionality's of the buoy were also enhanced in order to support, besides the underwater acoustics system, two different surface communication links: a radio link and a satelite link. The Data Radio Transmission System (DRTS) equipment of the buoy comprises a Multipurpose Electronic Unit (MEU), managing the communications and interfacing with DRTS and ATS, and a radio transmitter which allows data and command exchange between the buoy and a shore station. The DRTS and Acoustic Transmission System are permanently powered by a $24 \mathrm{~V}$ battery charged by two solar panels. In case of DRTS failure, the switch to a satellite transmission based on an Iridium system installed on the buoy is foreseen.

The DRTS of the shore station is a PC connected to three data channels: the shore VHF transmitter, a phone modem to get in touch the Iridium modem on the buoy and the Web net for remote command emission and data request and delivery.

The new functionalities of GEOSTAR have also call for the enhancement of the original DACS [4]. As for some sensors (e.g., gravity meter) the sampling rate was increased and new sensor packages were installed (e.g., chemical analyser, hydrophone), new acquisition channels were made active and the following functionalities were implemented: hourly-based data storage; automatic event detection on the seismometer and hydrophone data; transmission of seismometer wave-forms.

The DACS interface to the communication system was properly enhanced in order to make data and status parameter available for transmission to the communication system: the communication can be started by any of the ORION network nodes. The DACS hardware has been also upgraded in order to increase functions/capabilities and reliability with reduced power and volume requirements: new CPU boards with increased power, new status boards with additional sensors, scientific data acquired at 24 bit, status sensors acquired at 16 bit (12 bits in the previous version), boards managing up to $32 \mathrm{~GB}$ on hard disk and 1 Gbyte on flash card.

As already mentioned, the ORION project was requested by EC to be compatible with the ASSEM network. Accordingly, the DACS communication protocol matches the operation of ORION nodes within ASSEM.

The first long-term mission of ORION started in December 2003 and has been running at the time of preparation of this paper. The deployment site lays in the southern Tyrrhenian Sea at over $3300 \mathrm{~m}$ w.d. at the base of the Marsili submarine volcano, one of the larger seamount of the Mediterranean basin. ORION network includes GEOSTAR as main node, one satellite (Node 3) deployed around $1 \mathrm{~km}$ a part, and a surface buoy in acoustic connection with GEOSTAR and radio link with the on-shore station sited inside the INGV observatory of Gibilmanna (Northern coasts of Sicily). The GEOSTAR and the satellite equipment's are listed in Table I.

An additional node of ORION (Node 4), equipped with a three-component broad-band seismometer, a three-component single-point current meter, a hydrophone and a methane sensor, was deployed as node of the 
ASSEM network during a joint experiment on-going in the Corinth Gulf (Central Greece, Fig. 4e). This ORION node is in acoustic link with the ASSEM surface buoy and is able to transmit the data acquired to a dedicated server accessible through the web.

\section{DATA FROM THE SINGLE-FRAME PLATFORM}

In this section we present some examples of data acquired by the single-frame seafloor multiparameter system acquired during completed missions. (GEOSTAR 1 and 2, and $\mathrm{SN}-1$ missions). A more exhaustive presentation of the data, interpretation and discussion can be found in [1],[3].

In Fig. 5 data from the CTD of GEOSTAR acquired during the shallow water mission are presented. In particular samples of pressure, density and salinity are plotted over time. In Fig. 6 the broad-band recording of an earthquake occurred in central Italy $\left(M_{L}=4.6\right)$ in reported. It was acquired by the 3-components broad-band seismometer of GEOSTAR during the shallow water mission. In Fig. 7 is presented an elaboration of the ADCP data showing the shear magnitude over the whole mission period. In dark red colour the deepening of the pycnocline is evidenced [3]. In Fig. 8 a set of teleseismic events recorded by the gravity meter during the GEOSTAR deep-sea mission is presented. In Fig. 9 an earthquake sequence occurred during the last Etna volcano (southern Italy) eruption is shown as recorded by $\mathrm{SN}-1$ which was deployed at a distance of around $30 \mathrm{~km}$ from the volcano.

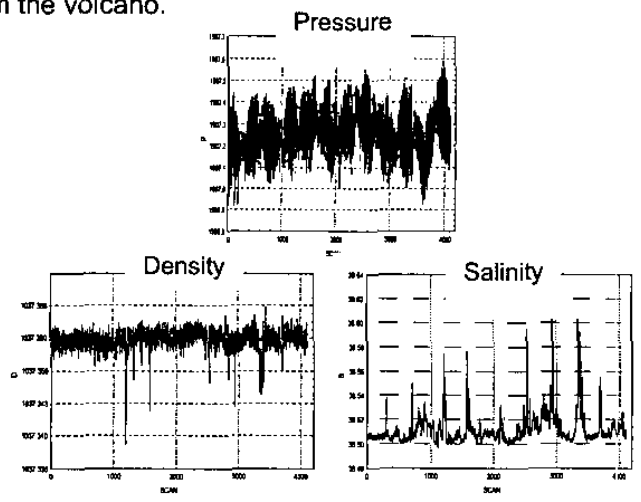

Fig. 5. An example of data collected by the CTD during the GEOSTAR shallow water mission of GEOSTAR: pressure density and salinity over time mission.

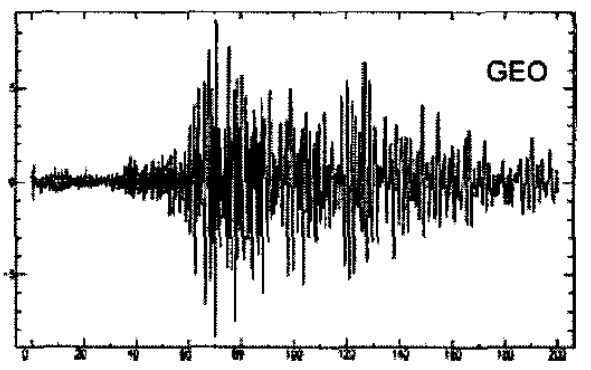

Fig. 6. Vertical component (in $\mathrm{mm}$ ) of the recording of an earthquake occurred in central Italy $\left(M_{L}=4.6\right)$ acquired during the shallow water mission of GEOSTAR by the 3-component broad-band seismometer.

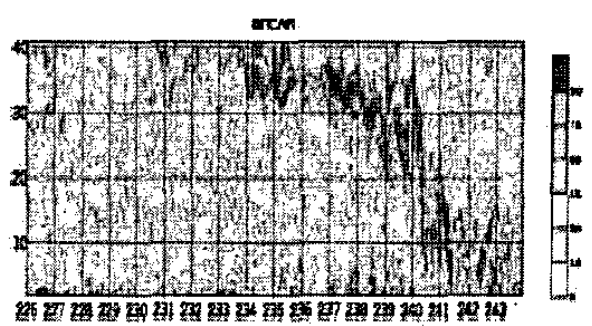

Fig. 7. Shear magnitude $S\left(\mathrm{~mm} / \mathrm{s} ; S=\sqrt{\left[(d U / d z)^{2}\right.}+\overline{(d V / d Z)^{2}}\right)$ from the ADCP data acquired during the shallow water mission of GEOSTAR. $S$ variation with depth ( $y$-axis) is plotted versus time (Julian days of the mission). The red colour marks the abrupt deepening of the pycnocline.

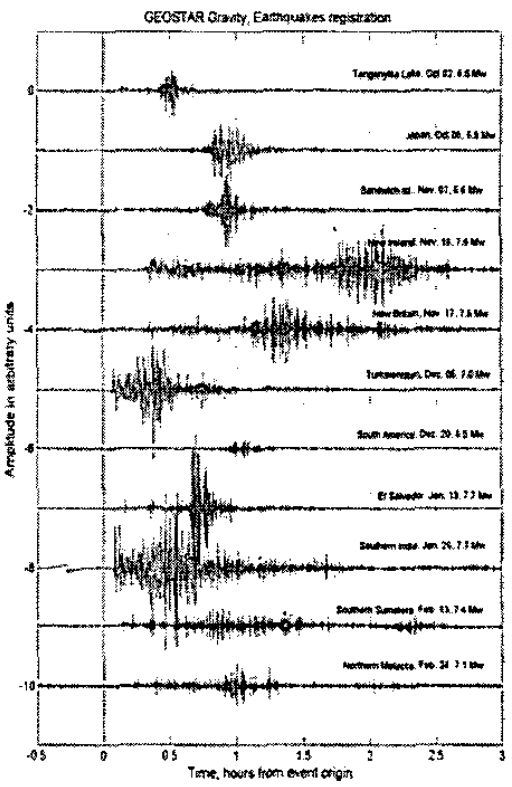

Fig. 8. teleseismic events recorded by the gravity meter of GEOSTAR during the deep-sea mission. The prototype was developed by the Italian Istituto di Fisica dello Spazio Interplanetario in collaboration with INGV.

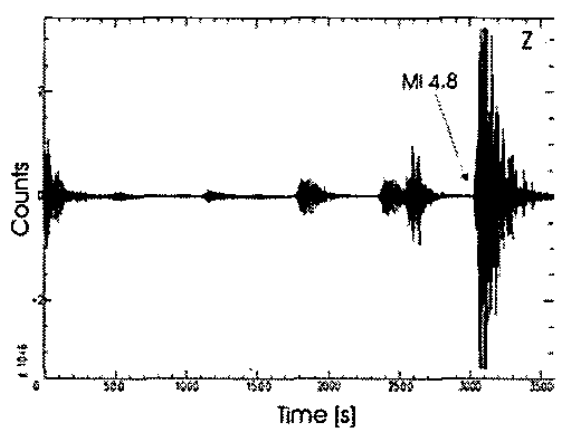

Fig. 9. Sequence of events occurred during the Etna eruption of 2002-2003 recorded by the broad-band seismometer of $\mathrm{SN}-1$. 


\section{CONCLUSIONS}

GEOSTAR and derived platforms and ORION seafloor observatory network have been tested in deep seafloor during long-term mission and demonstrated to be manageable from the surface through MODUS vehicle. The assets of these platform reside in the reliability of the whole system, the possibility of near-real-time communications and the data quality. The possibility to perform a quick comparison of data series of different sensors makes easy the development of a multiparameter data analysis. The platforms are perfectly compatible and can be easily re-configured depending on the specific applications.

All these features fit the EC requirements outlined within the framework of specific programmes, as for instance the Global Monitoring for Environmental and Security (GMES) presently running.

\section{Acknowledgements}

The Authors wish to thanks the partners of the projects mentioned in the paper:

GEOSTAR: Istituto Nazionale di Geofisica e Vulcanologia (Paolo Favali, Giuseppe Smriglio); Istituto di Scienze Marine (ISMAR)-CNR, Settore Geologia Marina (Michael P. Marani); Tecnomare-ENI SpA (Francesco Gasparoni); Technische Universität Berlin (Günther Clauss); Techniche Fachhochschule- Berlin (Hans Gerber); IFREMER (Jean Marvaldi); CNRS-Laboratoire de Océanologie et de Biogeochemie (Claude Millot); ORCA Instrumentation (now Sercel, Underwater Acoustic Division) (Jean-Michel Coudeville).

GEOSTAR 2: Istituto Nazionale di Geofisica e Vulcanologia (Paolo Favali, Giuseppe Smriglio); Tecnomare-ENI SpA (Francesco Gasparoni); Technische Universität Berlin (Günther Clauss); Techniche Fachhochschule- Berlin (Hans Gerber); IFREMER (Jean Marvaldi); CNRS-Laboratoire de Océanologie et de Biogeochemie (Claude Millot); ORCA Instrumentation (now Sercel, Underwater Acoustic Division) (Jean-Michel Coudeville); Institut de Physique du Globe de Paris (Jean-Paul Montagner).

ORION-GEOSTAR-3: Istituto Nazionale di Geofisica e Vulcanologia (Paolo Favali, Laura Beranzoli); Istituto di Scienze Marine (ISMAR)-CNR, Settore Geologia Marina (Fabiano Gamberi); Tecnomare-ENI SpA (Francesco Gasparoni); Technische Universität Berlin (Günther Clauss); Techniche Fachhochschule- Berlin (Hans Gerber);GEOMAR (Emst Flueh); IFREMER (Jean Marvaldi); ORCA Instrumentation (now Sercel, Underwater Acoustic Division) (Michel Nicot).

SN-1: Istituto Nazionale di Geofisica e Vulcanologia (Laura Beranzoli); University of Roma 3 (Claudio Faccenna); University di Catania (Stefano Gresta); University of Messina (Giancarlo Neri); University of Palermo (Dario Luzio); Istituto Nazionale di Oceanografia e Geofisica Sperimentale (Marino Russi); Istituto di Scienze Marine (ISMAR)-CNR, Settore Geologia Marina (Fabiano Gamberi, Michael P. Marani); Istituto di Fisica dello Spazio Interplanetario-Istituto Nazionale di Astrofisica (Valerio lafolla); Tecnomare-ENI SpA (Francesco Gasparoni); Technische Universität Berlin (Günther Clauss); Techniche Fachhochschule- Berlin (Hans Gerber); GEOMAR (Ernst Flueh); University of Hamburg (Torsten Dahm).
MABEL: Istituto Nazionale di Geofisica e Vulcanologia (Paolo Favali, Massimo Calcara); Tecnomare-ENI SpA (Francesco Gasparoni); Istituto Nazionale di Oceanografia e Geofisica Sperimentale (Renzo Mosetti); Technische Universität Berlin (Günther Clauss); Techniche Fachhochschule- Berlin (Hans Gerber); Collaborations:Alfred Wegener Institute for Polar Sciences (Wilfried Jokat); Istituto Antartico Argentino (José Febrer).

ASSEM: IFREMER (Jean-Francois Rolin, Jerome Blandin); Institut de Physique du Globe de Paris (Pierre Briole); Istituto Nazionale di Geofisica e Vulcanologia (Giuseppe Etiope); Hellenic Center for Marine Research (Vasilis Lykousis); University of Patras (George Ferentinos); CAPSUM Technologie Center $\mathrm{GmbH}$ (Michel Masson); Norges Geotekniske Institutt (James Strout); FUGRO Engineers SAINV (former Thales-geosolution, Steven Smolders, C. R. Golightly).

Special thanks to Dr. Claudio Viezzoli and Mr. Marcantonio Lagalante (marine logistics), the Captains Emanuele Gentile and Vincenzo Lubrano, and the crew of RN Urania, Capt. Alfio Di Giacomo and the crew of motopontoon Mazzarò

\section{REFERENCES}

[1] L. Beranzoli, T. Braun, M. Caicara, D. Calore, R. Campaci, J. M. Coudeville, A. De Santis, G. Etiope, P. Favali, F. Frugoni, J-.L. Fuda, F. Gamberi, F. Gasparoni, H. Gerber, M. Marani, J. Marvaldi, C. Millot, P. Palangio, G. Romeo, and G. Smriglio, "European seafloor observatory offers new possibilities for deep-sea study", EOS, Trans., AGU, 81(5), pp. 45-49, 2000.

[2] Beranzoli, P. Favali and G. Smriglio, (Eds.), "Science-technology synergy for research in marine environment: challenges for the XXI century", Science-technology synergy for research in marine environment: challenges for the XXI century", Amsterdam: Elsevier, 2002, p.268.

[3] L. Beranzoli, T. Braun, M. Calcara, P. Casale, A. De Santis, G. D'Anna, D. Di Mauro, G. Etiope, P. Favali, J.-L. Fuda, F. Frugoni, F. Gamberi, M. Marani, C. Millot, C. Montuori, and G. Smriglio, "Mission results from the first GEOSTAR observatory (Adriatic Sea, 1998)", Earth Planets Space, vol. 55, pp. 361-373, 2003.

[4] L. Beranzoli, D. Calore, P. Favali, J. Marvaldi and M. Nicot, "ORION-GEOSTAR-3: A Prototype of Seafloor Network of Observatories for Geophysical, Oceanographic and Environmental Monitoring", Proceedings of the 14th International Offshore and Polar Engineering Conference, vol. II, pp. 371-376, May 2004.

[5] M. Berta, F. Gasparoni, and M. Capobianco, "Abyssal Benthic Laboratori (ABEL): a novel approach for long-term investigation at abyssal depths", J. Mar. Syst., vol. 6, pp. 211-225, 1995.

[6] S. Cenedese, M. Calcara, G. D'Anna, K-U. Evers, P. Favali and F. Gasparoni, "MABEL: The First Seafloor Observatory for Multidisciplinary Long-term Monitoring in Polar Environment", Proceedings of the 14th International Offshore and Polar Engineering Conference, vol. I, pp. 787-794, May 2004.

[7] G. Clauss, S. Hoog, F. Stempinski and H. Gerber , "Advanced Deepwater Intervention with MODUS - 
Latest Results from Model Tests and Full-Scale Operations", Proceedings of the 14th International Offshore and Polar Engineering Conference, vol. II, pp. 377-386, May 2004.

[8] P. Favali and the SN-1 Team and the NEMO Collaboration, "SN-1: the first node of the Italian seafloor observatory network - background and perspective", Proceedings of the $3^{\text {rd }}$ International Workshop on Scientific Use of Submarine Cables and Related Technologies", pp. 19-24, June 2003.

[9] F. Gasparoni, D. Calore, R. Campaci, and A. Marigo, "GEOSTAR-development and test of an innovative benthic station for long-term observations at abyssal depths", Proceedings of the IEEE Conference OCEANS '98, on CD-ROM, 1998.

[10] M F. Gasparoni, Calore D. and Campaci R., "From ABEL to GEOSTAR: development of the first European deep-sea scientific observatory", in Science-technology synergy for research in marine environment: challenges for the XXI century, C L. Beranzoli, P. Favali and G. Smriglio Eds., Amsterdam: Elsevier, 2002, pp. 143-159.
[11]J. Marvaldi, J. Blandin, Ch. Podeur, J.-M. Coudeville, J. Antoine, D. Barbot, D. Fellmann, and D. Rhodes, "GEOSTAR-development and test of a communication system for deep-sea benthic stations", Proceedings of the IEEE Conference OCEANS '98, on CD-ROM, 1998.

[12]V. Rigaud, D. Semac, M. Nokin, DESIBEL Team, G. Tietze, H. Hamann, V. Goetz, and A. Pascoal, "New methods for Deep-Sea Intervention on future Benthic Laboratories, DESIBEL Project-Final Results, Comparison of concepts and at sea validation", Proceedings of the IEEE Conference OCEANS '98, on CD-ROM, 1998.

[13]H. Thiel, K. O. Kirstein, C. Luth, U. Luth, G. Luther, L. A. Meyer-Reil, O. Pfannkuche, and M. Weydert, "Scientific requirements for an abyssal benthic laboratory", J. Mar. Syst., vol. 4, pp. 421-439, 1994. 